\section{Residência em Psiquiatria: enquete nacional discorda da posição da Comissão Nacional de Residência Médica}

Psychiatric Residence: findings from a national survey disagree with the National Committee of Medical Residency

Sr. Editor,

Editorial recente desta revista retomou a necessidade de aprimoramento do ensino provido pelos programas de Residência Médica em Psiquiatria (RMP) no Brasil, enfatizando as conclusões de um relatório da Associação Mundial de Psiquiatria (WPA), o qual recomenda uma relação de temas e estágios, além de um tempo mínimo de três anos de formação. ${ }^{1}$ Há quatro anos temos de acomodar a decisão da Comissão Nacional de Residência Médica (CNRM) de manter o período mínimo de dois anos para a RMP, a despeito da posição contrária da Associação Brasileira de Psiquiatria (ABP). ${ }^{2}$

O que, na época, embasara a reivindicação da $A B P$ foi uma enquete postal conduzida com os então coordenadores de todos os 34 programas credenciados de RMP e com todos os 22 professores titulares da especialidade. O questionário de três páginas a eles remetido abordava temas referentes à seleção de candidatos, duração do programa, cursos e estágios obrigatórios e critérios de avaliação. As respostas foram coletadas por meio de escalas tipo likert, com cinco opções de resposta. Obtivemos informações de 24 (71\%) coordenadores de programas e de 13 (59\%) professores titulares. (Tabela 1) Os resultados dessa enquete circularam restritamente na $A B P$. Julgamos oportuno divulgá-los mais amplamente, uma vez que carecemos de pesquisas recentes a esse respeito (lamentavelmente nosso país não figura no relatório da $W^{2} A^{3}$ ) e, principalmente, pelo fato de que, até o presente momento, sugestões fundamentais de nossa Associação não foram encampadas pela CNRM.

Os resultados da enquete confirmavam: a legislação estava defasada. Na prática, os programas de RMP tinham ido à frente, introduzindo novos cursos e estágios à medida que o conhecimento e os serviços foram se aperfeiçoando. Isso ocorreu, por exemplo, nas áreas de dependências químicas e de interconsulta. Essa última, já no início da década de 90, era parte integrante do treinamento de $90 \%$ dos programas. ${ }^{4}$ No entanto, tem-se tornado cada vez mais difícil - praticamente impossível - dar conta de um conteúdo teórico e prático crescente, sem que se estenda o tempo de treinamento.

Alguns programas de Residência Médica prolongaram, deliberadamente, o período de treinamento para além do limite mínimo determinado pela CNRM. Isso, no entanto, dá margem a dissensões, uma vez que o médico residente tem, por lei, direito assegurado de requerer certificado de conclusão, decorrido o tempo legalmente estabelecido.

Esperamos que os resultados dessa enquete dêem força à nossa reivindicação: são necessários pelo menos três anos para formar um psiquiatra (aproximadamente $3 / 4$ das respostas em nossa enquete). Três anos ou mais é o que já acontece em $88,4 \%$ dos programas de RMP avaliados pela WPA em vários países do mundo, diversos deles latino-americanos (Argentina, Uruguai, Chile, Colômbia e México). ${ }^{3}$

Neury José Botega

Departamento de Psicologia Médica e Psiquiatria, Faculdade de Ciências Médicas, Universidade Estadual de Campinas (UNICAMP), Campinas (SP), Brasil

Marco Antônio Alves Brasil Instituto de Psiquiatria, Universidade Federal do Rio de Janeiro (UFRJ), Rio de Janeiro (RJ), Brasil

Miguel Roberto Jorge Departamento de Psiquiatria, Escola Paulista de Medicina, Universidade Federal de São Paulo (UNIFESP), São Paulo (SP), Brasil

Financiamento: Inexistente

Conflito de interesses: Inexistente

\section{Referências}

1. Zanetti MV, Coelho BM, Lotufo Neto F. Residência em Psiquiatria no Brasil: uma contribuição para o debate. Rev Bras Psiquiatr. 2005;27(1):9-10.

2. Botega NJ. Residência Médica: como melhorar sem os três anos? Rev Bras Psiquiatr. 2001;23(3):124-5.

3. World Psychiatric Association. Institutional Program on the Core Posgraduate Training Curriculum for Psychiatry. Virginia: World Psychiatric Association; 2002.

4. Botega NJ. Consultation-liaison psychiatry in Brazil: psychiatric residency training. Gen Hosp Psychiatry. 1992;14(3):186-91. 


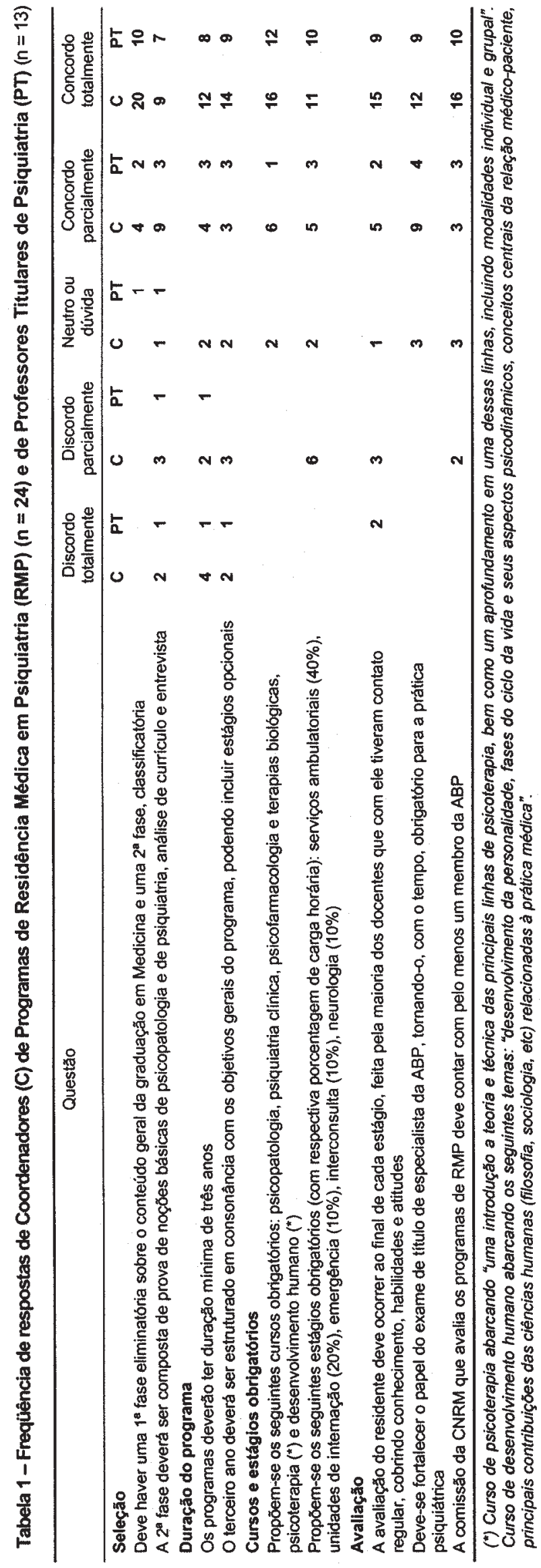

Expansão do Programa Saúde da Família (PSF) e identificação de problemas relacionados ao uso de álcool no Brasil

Expansion of the Family Health Progiram (FHP) and identification of alcohol-related problems in Brazil

Em 1994, o Ministério da Saúde do Brasil implantou o Programa Saúde da Família (PSF) com propósito de "reorganizar a prática da atenção à saúde em novas bases e substituir o modelo tradicional, levando a saúde para mais perto da família e, com isso, melhorar a qualidade de vida dos brasileiros". ${ }^{1}$ A estratégia do PSF prioriza as ações de vigilância, prevenção, promoção e recuperação da saúde, de forma integral e contínua.

Os problemas relacionados ao uso de álcool vêm sendo reconhecidos como relevantes agravos à saúde pública no Brasil, relacionando-se a acidentes de trânsito e a impactos relevantes nos anos potenciais de vida perdidos por doença ou morte precoce..$^{2-3}$

Reconhecendo a potencialidade do PSF em tornar-se uma importante estratégia para abordagem de problemas na área de saúde mental, ${ }^{4}$ o presente trabalho apresenta dados sobre a relação entre a expansão da cobertura do PSF na população com mais de 15 anos, no período de 1998 e 2004, e sua relação com a identificação nesta população de pessoas com "alcoolismo", utilizando o Sistema de Informações da Atenção Básica do Sistema Único de Saúde (SIAB/SUS).

Observa-se um incremento progressivo no número absoluto de pessoas cadastradas no PSF ao longo dos anos avaliados (Tabela 1). Considerando os extremos do período, o número passou de 2.058.054 para 48.364.457, havendo aumento superior a 23 vezes. Verificou-se que, no mesmo período, houve um aumento superior a 13 vezes no número de pessoas cadastradas com "alcoolismo", elevando-se de 28.821, em 1998, para 398.165, em 2004. Desta forma, verificou-se um declínio progressivo no percentual da população cadastrada no PSF identificada com "alcoolismo", passando de 1,4\%, em 1998, para cerca de 0,82\% em 2004; portanto uma redução em torno de $41,43 \%$. A redução do percentual de pessoas cadastradas com "alcoolismo" se correlaciona estatisticamente com o aumento da população cadastrada ( $p=0,001$, $r=-0,985, n=7$, Teste de Pearson).

Inicialmente, questiona-se a utilização da categoria "alcoolismo" no SIAB/SUS, visto que esta sequer faz parte da nomenclatura de doenças adotadas no Brasil, o que dificulta compreender qual dimensão do uso problemático de álcool está sendo registrada. A expansão da cobertura (evidenciada pelo número de pessoas cadastradas) veio acompanhada de uma redução na identificação das pessoas com "alcoolismo" (redução do percentual de cadastrados com "alcoolismo"), apontando para diminuição da capacidade de vigilância em saúde. Considera-se improvável que esta redução esteja associada à atuação do PSF junto à população, uma vez que, embora as ações na área de álcool e drogas tenham sido apontadas como essenciais, estas não foram efetivamente implantadas no âmbito do PSF. ${ }^{4}$ Por outro lado, pode-se considerar esta identificação como baixa em todos os anos investigados, se compararmos com dados nacionais que apontam para uma prevalência da dependência ao álcool em torno de $11,2 \%$ na população geral do país. ${ }^{5}$ 